\title{
The Flocculation of Suspended Matter by Paramecium caudatum
}

\author{
By C. R. CURDS \\ Department of Botany and Zoology, Chelsea College of Science and Technology
}

(Received 30 July 1962)

\section{SUMMARY}

Paramecium caudatum has been shown to cause the flocculation of Indian ink particles. Flocculation has been demonstrated to be due to: (a) the secretion of a substance ' $\mathrm{P}$ ', a carbohydrate whose monosaccharide constituents are glucose and arabinose, $(b)$ the ingestion of particles by the cell which are then bound together by a sticky mucoprotein. Substance ${ }^{6} \mathrm{P}$ ' is adsorbed on to Indian ink particles present, which results in a change of their surface charge and the aggregation into floccules. Substance ' $\mathrm{P}$ ' has been labelled with $\left[{ }^{14} \mathrm{C}\right]$ glucose which then appeared in the floccules.

\section{INTRODUCTION}

Many species of protozoa are known to occur in large numbers together with bacteria and fungi in the activated sludge process for the purification of sewage, but the significance of the protozoa and the part they might play in the purification process is not fully understood. Since 1942 several investigators have attempted to assess the part played by protozoa in the flocculation of suspended solids by activated sludge. Jenkins (1942) suggested that $40 \%$ of sewage purification by the activated sludge method was due to the flocculation of colloids, suspended matter and bacteria; he came to the conclusion that the protozoa were not the primary agents in bringing about flocculation since this could occur when protozoa were absent. Pillai (1941, 1942), Pillai \& Subrahmanyan (1942a, b), and Pillai, Wadhwani, Gurbaxani \& Subrahmanyan (1947) maintained that the peritrichous ciliates such as Epistylis and Vorticella were mainly responsible for the flocculation, but were unable to explain how the protozoa brought this about. Barker (1946) showed that Paramecium caudatum could induce flocculation. Watson (1945) first suggested a way in which protozoa might cause flocculation; he showed by staining techniques that the soil ciliate Balantiophorus minutus secreted a 'mucin' which stuck together the suspended soil particles and bacteria, thus forming floccules. Sugden \& Lloyd (1950) showed by using Indian ink and DDT powder that the peritrich Carchesium induced flocculation in a similar manner. To investigate some of the problems involved, a certain number of dominant protozoan species from activated sludge are being examined from this point of view by means of culture techniques. The present paper reports the results of preliminary investigations of $\boldsymbol{P}$. caudatum. 


\section{METHODS}

Materials and culture methods. Samples of activated sludge were collected from the pilot-scale plant at the Water Pollution Research Laboratory (DSIR), Stevenage, and from the Northern Outfall Sewage Works, London. After numerous experiments with hay infusions, pea extracts and Oxoid nutrient broth it was found that the best medium for Paramecium caudatum was a mixture of equal volumes of $0 \cdot 3 \%$ lettuce extract and $\mathbf{0 \cdot 3} \%$ coagulated egg yolk extract (Levine, 1959); this will be referred to as EL medium.

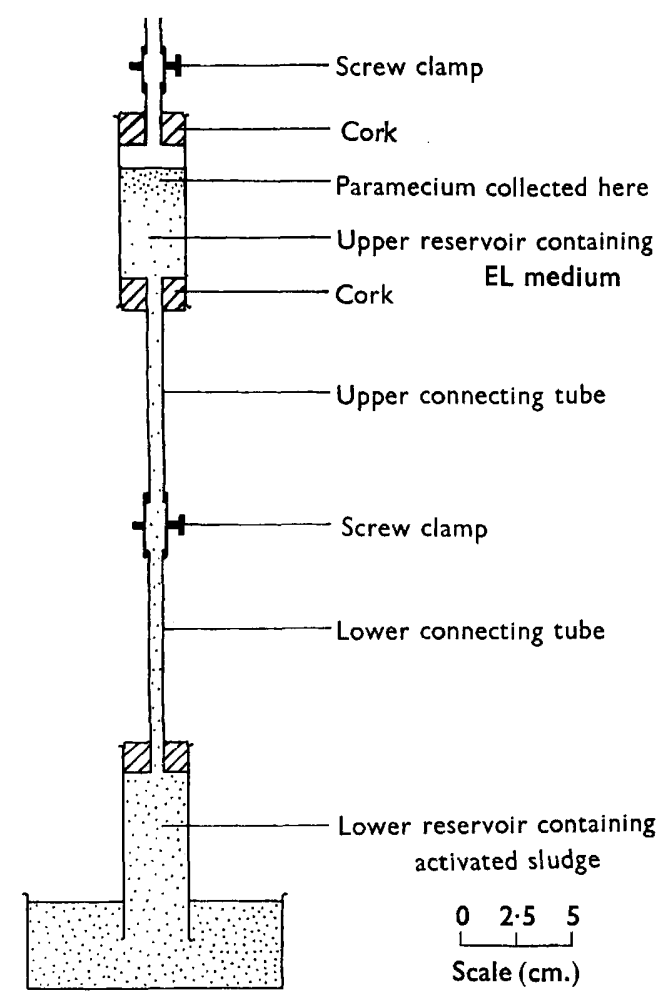

Fig. 1. Apparatus used for the separation of Paramecium caudatum from activated sludge.

Stock cultures were separated from the sludge in the apparatus shown in Fig. 1 by taking advantage of the negative geotaxis shown by Paramecium caudatum. Protozoa were collected from the upper reservoir after 4-8 hr. and put into fresh EL medium. Individual animals were picked out with a micropipette and introduced singly into a fresh culture medium. These individuals divided asexually to produce clones.

Analytical methods. The anthrone test used for the micro-estimation of carbohydrates was as described by Trevelyan \& Harrison (1952); an EEL portable colorimeter with a red filter OR I was used. Carbohydrates were hydrolysed by refluxing with $2 \mathrm{~N}$-hydrochloric acid for $8.5 \mathrm{hr}$. The monosaccharide derivatives produced 
were identified by paper chromatography by the descending technique. The butanol + acetic acid + water $(4+1+5$ by vol.) solvent was run overnight on a Whatman no. 1 paper. The papers were sprayed with aniline hydrogen phthalate and heated at $100^{\circ}$ for 5 min.

Radio-chemical methods. Uniformly labelled $\left[{ }^{14} \mathrm{C}\right]$ glucose $(0 \cdot 24 \mathrm{mg} . ; 0 \cdot 1 \mathrm{mc}$.) was eluted from the paper received from The Radiochemical Centre (Amersham) in $3 \mathbf{~ m l}$. distilled water, and the solution evaporated to dryness under an infrared lamp. To the resulting crystals $15 \mathrm{ml}$. of a clonal suspension of Paramecium caudatum containing $10 \mathrm{mg}$. A.R. glucose carrier were added. The clonal suspension was left at room temperature for 5 days and then transferred to a smaller version of the separating apparatus shown in Fig. 1, containing sterile EL medium with $5000 \mathrm{u}$. penicillin $/ \mathrm{ml} .+250 \mu \mathrm{g}$. streptomycin $/ \mathrm{ml}$. The protozoa swam up the tubes; this not only separated them from the radioactive source but also did a certain amount of washing free from bacteria. Paramecium caudatum was collected from the upper reservoir and put through a series of four washings in EL medium + antibiotics. Ten' of these organisms were finally picked out and counted for radioactivity in a solid scintillation counter.

\section{RESULTS}

With clonal suspensions as experimental material experiments were carried out which showed (1) that Paramecium caudatum and associated bacteria caused flocculation of Indian ink particles; (2) that $P$. caudatum rather than the associated bacteria were responsible for flocculation; (3) that Indian ink particles were not necessarily ingested before flocculation could occur; (4) that there was an accumulation of a sugar in a carbohydrate-free culture of $\boldsymbol{P}$. caudatum; (5) that there was an uptake and subsequent secretion of isotope into the culture medium by $\boldsymbol{P}$. caudatum grown in the presence of $\left[{ }^{14} \mathrm{C}\right]$ glucose; $(6)$ that $\boldsymbol{P}$. caudatum secretes a soluble substance ' $P$ ' which was responsible for flocculation.

\section{Experiment 1}

A boiling tube containing sterile EL medium was allowed to stand open to the atmosphere at room temperature for $\mathbf{2 4} \mathrm{hr}$., thus allowing bacteria to grow within the culture medium; it was then divided into two halves and 3 drops Indian ink added to each. One tube was inoculated with a large number of Paramecium caudatum and plugged with cotton wool, whilst the other was left plugged but uninoculated as a control. After 6 hr. it was observed that the tube containing Paramecium showed flocculation of the ink particles, which lay at the bottom of the tube as a black mass, whilst the control tube remained turbid. The control tube was kept a further 8 days and only then did the ink particles begin to settle out. The flocculated ink masses, collected from both tubes, were fixed in methanol, and stained for the 'mucin' found by Watson (1945) by using this author's methods and other more diagnostic histochemical techniques. The ink particles from the control tube gave negative results with all stains. The results (Table 1) show that the flocculated ink particles were bound together by a mucoprotein (or glycoprotein) when $\boldsymbol{P}$. caudatum was present. 


\section{Experiment 2}

A culture of Paramecium caudatum was washed eight times in sterile EL medium containing $5000 \mathrm{u}$. penicillin $/ \mathrm{ml}$. and $250 \mu \mathrm{g}$. streptomycin $/ \mathrm{ml}$., to prevent the growth of bacteria. A sterile micropipette was used for each wash. The protozoa from the final washing were inoculated into a sterile test tube containing $15 \mathrm{ml}$. EL medium with $5000 \mathrm{u}$. penicillin $/ \mathrm{ml}$. and $250 \mu \mathrm{g}$. streptomycin $/ \mathrm{ml}$. and three drops Indian ink. The tube was plugged with cotton wool and covered with tin-foil. Flocculation took place within $3 \mathrm{hr}$. Immediately, a tube of nutrient agar ( $1.5 \mathrm{~g}$. agar in $100 \mathrm{ml} .0 \cdot 3 \%$ Oxoid nutrient broth) was streaked with the culture medium and incubated at $28^{\circ}$. A single colony of bacteria grew after 2 weeks; this was grown and a bacterial culture obtained which showed no flocculation with Indian ink even after 3 weeks.

\section{Table 1. Staining reactions of Indian ink floccules produced} in the presence of Paramecium caudatum

Staining technique

Methylene blue

Dafranin

Southgate's mucicarmine

Periodic acid/Schiff *

PA/S after diastase*

Methylene blue extinction test*

Toluidine blue*
Result

$+\quad$ 'Tests used by Watson (1945). Show presence of

$+\quad$ PA/S positive polysaccharide present but unlike

$+\quad$ glycogen

pH 5-6 Diagnostic of protein-linked polysaccharide

Purple $+\beta$-metachromatic; diagnostic of protein-linked polysaccharide

* For methods see Pearce, Kramer \& Windrum (1960).

\section{Experiment 3}

This was devised to show whether or not the ink particles must be ingested before flocculation can occur. A drop of Indian ink was added to a test tube of Paramecium caudatum clonal suspension and the end covered by two layers of fine bolting silk and secured by a rubber band. The tube was inverted inside a boiling tube, and supported by a cork. The boiling tube contained a suspension of ink in EL medium. $\boldsymbol{P}$. caudatum, being negatively geotaxic, remained at the top of the inverted test tube whilst the bolting silk filter prevented stray protozoa from invading the medium in the boiling tube. This apparatus 'A' was left $\mathbf{2 4} \mathbf{~ h r}$. A control apparatus ' $B$ ' was set up consisting of a boiling tube containing ink in EL medium. Flocculation occurred in both test tube and boiling tube of apparatus ' $A$ ' but not in apparatus ' $B$ '. The staining reactions of the ink floccules in apparatus ' $A$ ' were positive as in Table 1 for those in the test tube, but negative for those in the boiling tube, which suggests a dual flocculation mechanism.

\section{Experiment 4}

The anthrone method for the micro-estimation of carbohydrates was used to show that a carbohydrate was being secreted by Paramecium caudatum and was accumulating in the culture medium. Twenty-five ml. of sterile $0.3 \%(w / v)$ Oxoid nutrient 
broth in distilled water, which gives only a weak reaction with anthrone, was filled into each of three $1 \mathrm{in}$. diameter tubes. Two tubes were inoculated with washed specimens of $\boldsymbol{P}$. caudatum in one drop of nutrient broth; tube 1 contained about three times the number of protozoa contained in tube 2 . The third tube acted as a bacterial control and was inoculated with a drop of protozoa-free culture medium. All three tubes were plugged with cottonwool and left for 5 days at room temperature. Samples were taken from each tube on days 0,2 and 5 , membranefiltered free from bacteria and the carbohydrate concentration estimated. Table 2 shows the increase in carbohydrate concentration in the tubes inoculated with $\boldsymbol{P}$. caudatum. There was no increase in the control tube. As the concentration of carbohydrate increased the degree of bacterial flocculation also increased.

Table 2. Showing accumulation of carbohydrate in Paramecium cultures in Oxoid nutrient broth by the anthrone method (Expt. 4)

\begin{tabular}{|c|c|c|c|c|c|}
\hline \multirow{3}{*}{$\begin{array}{c}\text { Tube } \\
\text { no. }\end{array}$} & \multicolumn{5}{|c|}{ Day } \\
\hline & Numbers & $\mathbf{0}$ & 2 & 5 & \multirow{2}{*}{$\begin{array}{c}\text { Flocculation } \\
\text { on the } \\
\text { 5th day* }\end{array}$} \\
\hline & paramecia* & \multicolumn{3}{|c|}{ Carbohydrate $(\mu \mathrm{g} . / \mathrm{ml})}$. & \\
\hline $\mathbf{I}$ & $\times \times \times$ & 12.5 & $21 \cdot 0$ & 46.5 & $\times x$ \\
\hline 2 & $\times$ & $12 \cdot 5$ & 12.5 & $22 \cdot 0$ & $\times$ \\
\hline $\mathbf{3}$ & $\mathbf{0}$ & $12 \cdot 5$ & $12 \cdot 5$ & $12 \cdot 5$ & $\mathbf{0}$ \\
\hline
\end{tabular}

Another experiment with the same numbers of paramecia as in tube 2 gave similar results.

* Estimated by eye.

\section{Experiment 5}

After feeding a clonal suspension of Paramecium caudatum for $2.5 \mathrm{hr}$. with uniformly labelled $\left[{ }^{14} \mathrm{C}\right]$ glucose the average activity was found to be 19-20 counts/ sec. (c.p.s.)/animal. Their activity remained constant after feeding a further 3 days. Five hundred radioactive organisms were picked out from the final washing and transferred to a burette containing $44 \mathrm{ml}$. suspension of Indian ink in antibiotics + EL medium. The particles flocculated within $24 \mathrm{hr}$. These floccules were counted for radioactivity. Twenty post-flocculation protozoa were pipetted from the top of the burette and counted; $0 \cdot 1 \mathrm{ml}$. of the burette medium was also counted. Table 3 shows that the activity of the protozoa fell from 20 to 0.3 c.p.s./organism, and this was accompanied by a gain in activity of the ink floccules and burette medium. $16 \%$ of the radioactivity secreted by the protozoa was concentrated in $0.016 \mathrm{~g}$. Indian ink floccules. Since the protozoa alone were labelled with the isotope, radioactive bacteria being removed by washing, the ink floccules can only have become radioactive because of the presence of the protozoa.

\section{Experiment 6}

A washed clone of Paramecium caudatum was put into $10 \mathrm{ml}$. sterile nutrient broth culture medium and dialysed immediately against $25 \mathrm{ml}$. distilled water overnight. A control was set up without Paramecium. A sample of the diffusate was membrane-filtered and found to give a positive reaction with anthrone. This carbohydrate must be soluble and will be referred to as substance ' $P$ '. The control diffusate did 
not react with anthrone. Two drops Indian ink were added to the diffusates; the control did not flocculate whereas the experimental diffusate did.

Table 3. Showing the uptake and subsequent secretion of ${ }^{14} \mathrm{C}$ by

Paramecium caudatum

\begin{tabular}{|c|c|c|c|}
\hline \multirow[b]{2}{*}{ escription of sample } & \multicolumn{3}{|c|}{ Activity (c.p.s.) } \\
\hline & $\begin{array}{l}\text { Total } \\
\text { count }\end{array}$ & $\begin{array}{l}\text { Background } \\
\text { count }\end{array}$ & Balance \\
\hline ium pre-flocculation & $196 \cdot 76$ & $0 \cdot 49$ & $196 \cdot 27$ \\
\hline shed flocculated Indian ink & $1188 \cdot 80$ & $0 \cdot 48$ & $1188 \cdot 32$ \\
\hline slation Paramecium & $7 \cdot 50$ & $0 \cdot 48$ & $7 \cdot 02$ \\
\hline red EL medium post-floceulation & $18 \cdot 71$ & $0 \cdot 46$ & $18 \cdot 25$ \\
\hline
\end{tabular}

The surface charge of a suspension of Indian ink particles in distilled water was measured by electrophoresis. The charge of the particles was found to be negative. On the addition of a solution of substance ' $P$ ', prepared as before, the surface charges changed. Some particles became positively charged, some were approximately one-quarter of the original negative charge, whilst some remained negatively charged as before. These differences in surface charge would account for the aggregation of the particles and the subsequent flocculation.

A strong solution of the ' $P$ ' substance was prepared, evaporated to dryness and hydrolysed. The monosaccharide derivatives produced were identified as glucose and arabinose. The Elson \& Morgan reaction for 2-amino sugars gave negative results; the method was as that of Kraan \& Muir (1957). Similar results were obtained by hydrolysing washed ink floccules produced by the ' $\mathrm{P}$ ' substance, which indicated that the ' $P$ ' substance was adsorbed by the ink particles.

\section{CONCLUSIONS}

From these experiments it is clear that a polysaccharide, substance ' $\mathrm{P}$ ', whose monosaccharide constituents are glucose and arabinose, is secreted by Paramecium caudatum into the surrounding medium. Suspended particles whose surface charge is negative will adsorb some of this polysaccharide, resulting in a change of charge and the aggregation of the particles to form floccules. Substance ' $\mathrm{P}$ ' appears to be the important factor in causing flocculation, but the staining reactions given in Table 1 show that a mucoprotein binds the floccules when Paramecium is present. Floccules produced by the ' $P$ ' substance alone gave negative staining reactions, indicating that two methods of flocculation are involved. Phase contrast microscopy of the peritrich Vorticella microstoma showed that ink particles entering the cell subsequently left as floccules. A similar process has been observed in the colonial peritrich Epistylis plicatilis. These floccules were collected with a micropipette; they gave staining reactions as in Table 1. This shows that there are at least two methods of flocculation, the first by a general secretion of substance ' $\mathrm{P}$ ', as observed in $\boldsymbol{P}$. caudatum and $V$. microstoma (also observed by me), and secondly by the ingestion of the ink particles, which are released by the cellbound by a mucoprotein. 
The function of the carbohydrate secretion is difficult to assess. Some bacteria have the ability to secrete mucopolysaccharides, and it has been suggested that this is a means of defence against protozoa (Stacey, 1953). The carbohydrate secreted by Paramecium caudatum might therefore be a similar defence against bacterial action. Assuming that the population of $\boldsymbol{P}$. caudatum in activated sludge is large enough, it will have a marked effect upon the flocculating properties of the sludge. The dominant species of activated sludge are the peritrichs, which have previously been shown by several workers to induce flocculation. $\boldsymbol{P}$. caudatum would therefore take its place among the other protozoa and bacteria in producing a combined flocculating effect upon the sludge.

I would like to thank my supervisor Dr E. M. Brown for her kind help and useful criticism, Dr S. R. Hughes for his supervision of the radiochemical work, Mr R. W. Edwards, Mr T. G. Tomlinson and other members of the Water Pollution Research Laboratory for their help and encouragement.

\section{REFERENCES}

Barker, A. N. (1946). The ecology and function of protozoa in sewage purification. Ann. appl. Biol. 33, 314.

Jenkins, S. H. (1942). The role of protozoa in the activated sludge process. Nature, Lond. $150,607$.

KraAN, J. G. \& Muir, H. (1957). The determination of glucosamine. Biochem. J. 66, 55 P.

Levine, L. (1959). Axenising Vorticella convallaria. J. Protozool. 6, 169.

Pearse, A. G. E., Kramer, H. \& Windrum, G. M. (1960). Histochemistry, theoretical and applied, 2nd ed. London: J. A. Churehill.

PillaI, S. C. (1941). The function of protozoa in the activated sludge process. Curr, Sci. $10,84$.

Pillai, S. C. (1942). Further studies on the role of the protozoa in the activated sludge process. Curr. Sci. 11, 437 .

Pillai, S. C. \& Subrahmanyan, V. (1942a). The role of the protozoa in the activated sludge process. Nature, Lond. $150,525$.

Pillat, S. C. \& Subrahmanyan, V. (1942b). The role of the protozoa in the aerobic purification of sewage. Nature, Lond. 154, 179.

Pillai, S. C., Wadhwani, T. K., Gurbaxani, M. I. \& Subrahmanyan, V. (1947). The relative efficiency of bacteria and protozoa in floceulation and oxidation of organic matter suspended in water. Curr. Sci. 16, 340.

Stacey, M. (1953). Bacterial polysaccharides. Endeavour, 12, 38.

Sugden, B. \& Lloyd, Lr. (1950). The clearing of turbid waters by means of the ciliate Carchesium; a demonstration. J. Inst. Sew. Purif. pt. 1, 16.

'Trevelyan, W. E. \& Harrison, J. S. (1952). Studies on yeast metabolism. (1) Fractionation and microdetermination of cell carbohydrates. Biochem. J. 50, 298.

Watson, J. M. (1945). Mechanisms of bacterial flocculation caused by protozoa. Nature, Lond. 155, 271. 